Japanese Psychological Research

1990, Vol. 32, No. 2, 55-65

\title{
The development of text comprehension monitoring activities
}

\author{
MOTOO MITSUDA ${ }^{1}$ \\ Deparment of Behavional Science, University of Tokushima, Minami-Josanjima, Tokushima 770
}

Relationships among text comprehension performance and comprehension monitoring activities in 4th-and 6th-graders were studied in an experiment that employed a comprehension monitoring tasks in which those subjects were required to rate their subjectively estimated achievements after their recognition tasks. The 6 th-graders showed causal relations among task-related metamemory activities and their text recognition performances. This time, influence of inserted question aids upon those causal relations were observed for both story and science text materials. The results were discussed in terms of subject's use and understandings of macrostructures of text materials that had those subjects use genre-specific reading skills.

Key words: metamemory, text comprehension, 4 th-and 6th-graders, macrostructures.

The present study is an attemot to depict the impacts of some cognitive/metacognitive variables upon young reader's efficiency as subjects discriminated their own correct recognition responses from incorrect ones. The author (Mitsuda, 1987) had shown that for younger child readers, inference recognition of macrostructures of the text had correlated negatively with their ratings for confidence in correctness of their own recognition responses, while positive correlations were obtained for verbatim recognition tasks. The results had been interpreted in terms of inefficiencies of young readers as they activated and utilized task-specific processing skills in their text comprehension activities.

Somehow in accord with those remarks, previous findings (e.g., Baker \& Brown, 1984) had shown that evolution of the metacognitive performance with age involved changes in both monitoring and self-regulatory aspects of processing which would enable older children to edit representations of prose units to see both causal and temporal orderiness among

1 The author is grateful to Naoko Mine and Hideki Saitoh, students of University of Tokushima, for their cooperation in running this experiment. episodic units of text materials, and also that younger ones were likely to rely upon verbatim or less elaborated representations of the text because of this in efficiency in making inference and monitoring their own processing activities to see schematic relations among each of the constituent paragraphs of the text materials.

From those results, it could be surmised that for 6th-graders, their own feelings of incompetence in such academic areas as Japanese or Science studies would have adversely affected their use of genrespecific processing skills, monitoring, and other metacognitive aspects of processing activities, while such detrimental effects of poor self-concepts would be less likely for younger ones.

The present study was directed to the above-mentioned issues: Its purpose was to depict some type of developmentally obtained efficiency of young readers as they monitored and controlled their own text processing activities. Here, it was supposed that for older children, their self-concepts in particular academic areas (e.g., Japanese or Science studies) would be critical determinants of their accuracy in discriminating their own correct recognition responses from incorect ones, 
while no such causal and/or correlational relationships would be the case for younger ones. This time, as indices of young reader's efficiency in monitoring their own comprehension activities, Confidence judgement Accuracy Quotients (CAQ) was obtained for both verbatim and inference recognition tasks. Here, the CAQ meant a ratio, the numerator of which meant differences between mean confidence rating values assigned to correct and incorrect recognition responses, while the denominator being the square roots for pooled variances of subject's confidence ratings for both correct and incorrect responses. The present study's selection of age levels to be compared and the CAQs were based on previous studies that utilized judgemental paradigms. For example, when 7th-graders (Mize, 1980) and mentally handicapped children (Brown \& Lawton, 1977) were given questions about expository or narrative text that those subjects had just read out, those subjects could judge correctness of their own responses to those questions. So that, it could be surmised that those judgemental paradigms could have helped to identify reader's strategy use as they monitored their own comprehension and also enabled to figure out relationships among subject's metacognitive strategy use, age levels and facilitative effects of instructional aids. Here, it was hypothesized that for older children, their own feelings of incompetence in Japanese or Science studies would somehow adversely affect their CAQs as those quotients were obtained for their recognition responses to science texts or story materials. For younger readers, however, such causal relations would be less likely to be obtained between their academic self-concepts in Science studies or Japanese and their actually obtained GAQs for both narrative and expository text materials.

Another concern of this study was how those correlations between subject's subjectively felt incompetence in genre-speci- fic processing skills and their actually obtained CAQs could be modified when question aids were interpolated between each of the constituent paragraphs of the text. Here, it was surmised that questions interpolated before each of the passage units would force readers to allocate their processing resources upon the questioned matters, while those inserted after each of those passage units would reinforce reader's task-appropriate processing activities that were carried out spontaneously.

\section{Method}

\section{Subjects}

Thirty-eight 4th-graders (19 males, 19 females, mean $C A=9: 6$ ) and 33 6th-graders (15 males, 18 females, mean $C A=$ 11:7) all attending to Elementary School affiliated to Naruto University of Teacher Education participated in this study. All of the subjects were supposed to be above average in intelligence. One third of each group was allocated to the nonquestion condition, and the other two thirds to forward- and backward-question conditions at random.

\section{Materials and Procedures}

Two experimental passages, one derived from a variation of science text that was originally edited for teachers, and the other from Henry's (1953) short story entitled "After twenty years" were employed. The former being identical to those of previous report (Mitsuda, Kurisu, \& Takeichi, 1985) and had described ecology of butterfies. It was about 800 words in length, while the latter was about 1500 words long and depicted how an offender was arrested because he was ignorant of the fact that as he came back to see his parted friend after a long departure of twenty years, the friend whom the offender wanted to see again had been a police officer patrolling around the street. 
Each of those text was divided into four constituent paragraphs, and was presented in a booklet form with one paragraph printed upon a separate sheet of a booklet. Other procedures of inserting question before (forward-question) and after (backward-question) each of the constituent paragraphs, recognition tests, and 5-point rating of confidence in correctness of those recognition responses were nearly identical to those of the author's previous report (Mitsuda, 1987). Here the experimenter told subjects that everytime after they read out each of two texts, they were to answer questions about those texts, and also that this time they would be asked to mark, in a forced-choice manner, the most appropriate response items among alternatives. Additionally, after each of those recognition responses were obtained, the subjects were asked to rate, on 5-point rating scales, how they were sure they had answered correctly to each of those questions about contents of the text. For each of the text materials, twelve test sentences were employed for both of the recognition tests and the above-mentioned confidence rating tasks. Additionally, partial recall tests of the texts and the confidence ratings for subject's own academic self-concepts were administered after those recognition tests.

\section{Results}

For descriptive purposes, correlations among those recognition remarks, their CAQs (Confidence Accuracy Quotients), and subject's self ratings obtained for their own academic proficiencies were computed for materials, grades (6th- and 4th-) and for the above-mentioned conditions of inserted question aids. The results were shown in Table 1.

Separate step-wise multiple regression analyses were carried out to allow a comparison of 4th- and 6th-graders in terms of how well the combined sets of retention variables, as well as subject's acade- mic self-concepts, were predictive of their CAQ remarks. Summary multiple regression data to predict verbatim CAQs were presented in Table 2.

The structure of correlational relations in Table 1 was further investigated by means of path models to depict structural relations that might characterize patterns of those intercorrelations. In an attempt to show how variances in those CAQ remarks could be explained in terms of those retention variables and subject's academic self-concepts, models to be analyzed were shown in Fig. 1 and Fig. 2, with their arrows representing significant causal orderings.

A glance of Table 1 and Fig. 1 showed that direct influence of verbatim recognition remarks on their $\mathrm{CAQ}$ remarks was strongest as the 6th-graders were given no question aids while least correlations were obtained as they were given question aids after each of the constituent passage units of the science text. The results obtained from separate ANOCOVAs with two factorial (age $\times$ inserted questions) design showed that for the 6th-graders, overlap between verbatim recognition and their CAQ remarks was minimized as they were given question aids after each of the constituent units of those science text $(r=.59)$ and maximized $(r=.92)$ when they were given no questions, while no differences in CAQ remarks were seen for the 4thgraders. The question mode $\times$ subject interaction was significant $(F(2,65)=6.001$, $p<.01$ ).

For verbatim recognition of story materials, however, just the reverse was the case: Correlation between recognition remarks and their CAQs was least $(r=.677)$ for non-questioned subjects while highest ones $(r=.753)$ were obtained as subjects were given question aids after each of the constituent paragraphs of the passages. Furthermore, except those of backwardquestioned conditions, the 4th-graders showed higher correlations as compared to the 6th-graders: The results of ANO- 


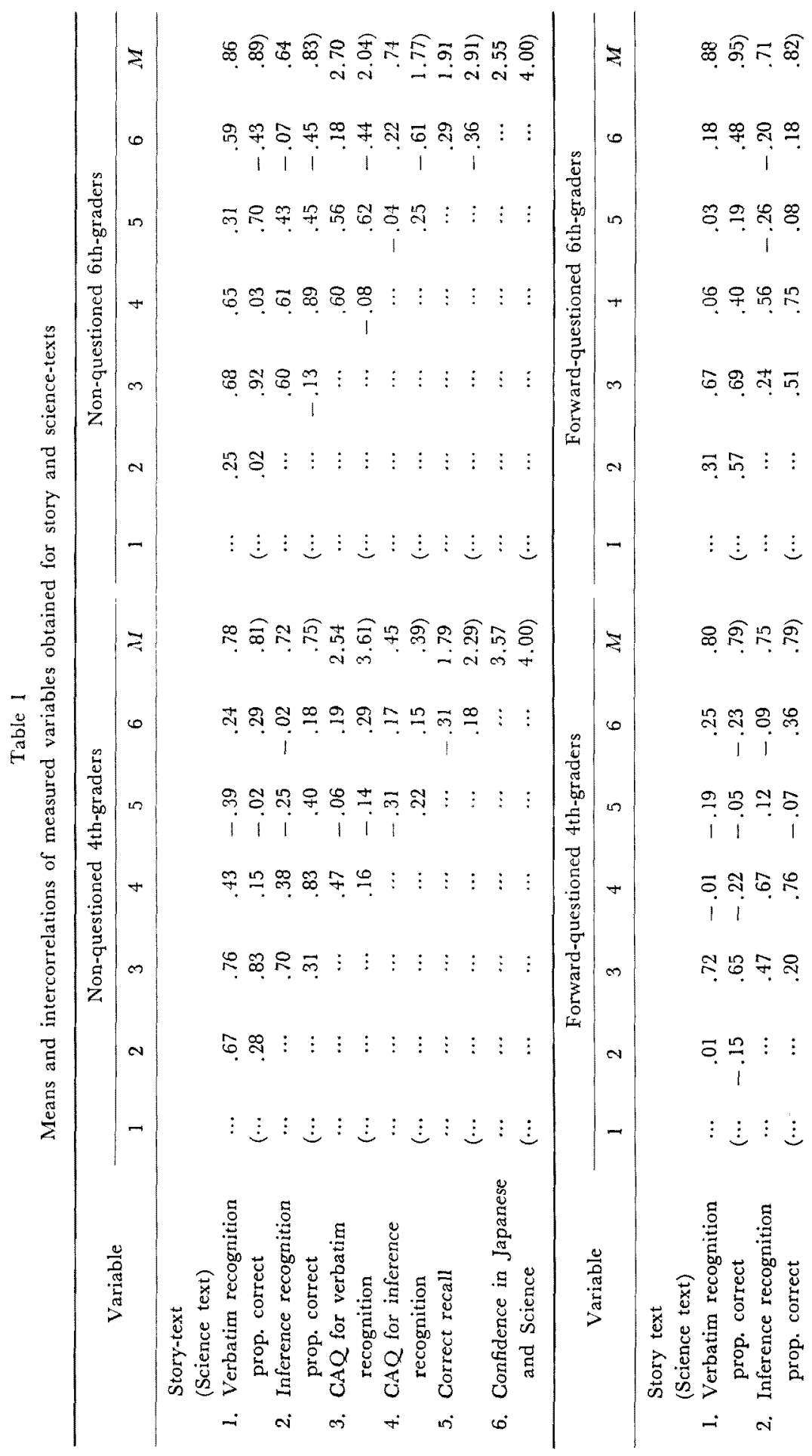




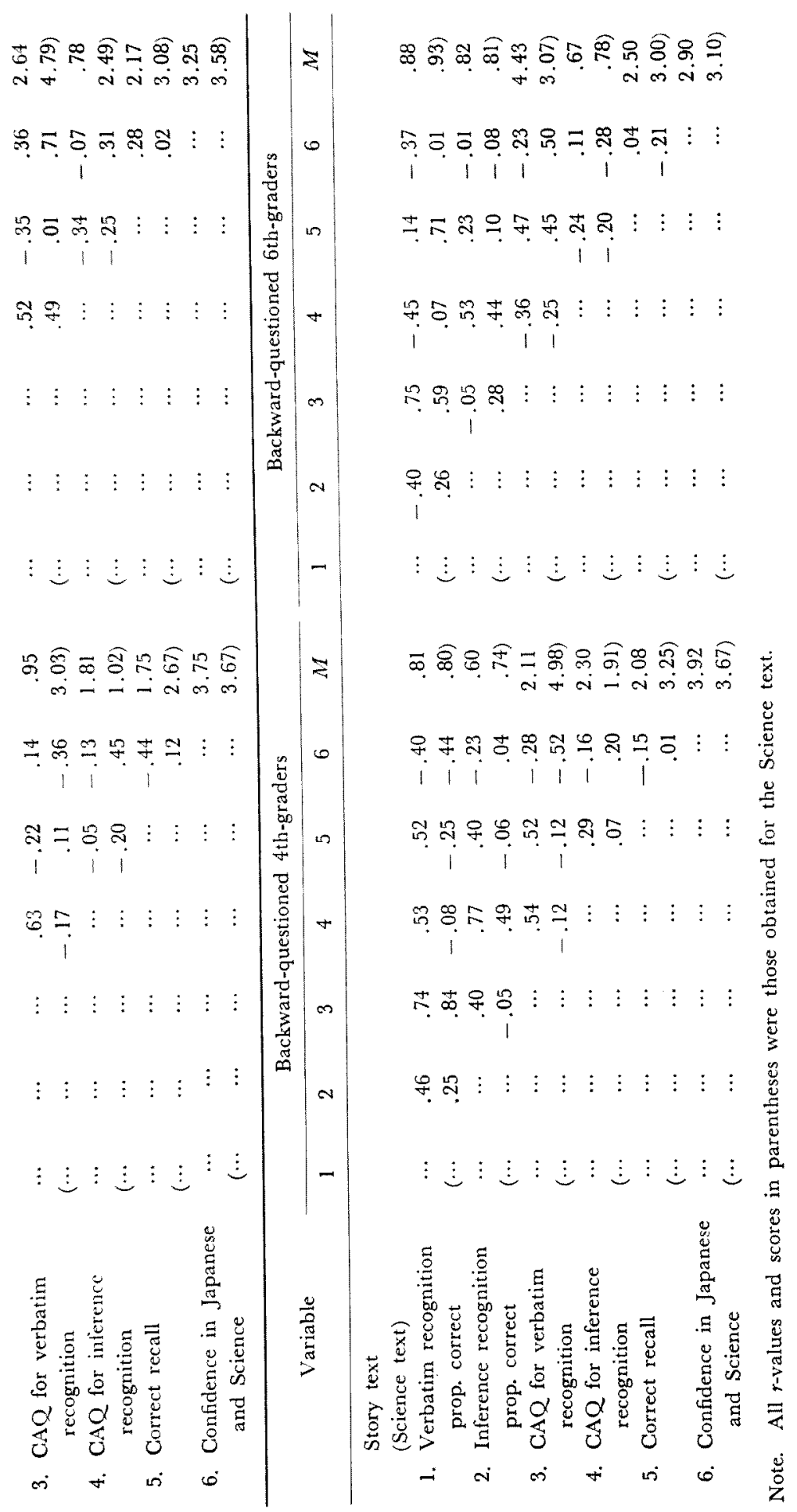


Table 2

Linear stepwise regression of CAQs on cognitive-metacognitive variables

\begin{tabular}{|c|c|c|c|c|c|c|}
\hline Grade & inserted question & material & step & variable & $R$-square & $F$ \\
\hline \multirow[t]{3}{*}{$6 \mathrm{th}$} & \multirow[t]{3}{*}{ Non-question } & \multirow[t]{2}{*}{ Story } & 1 & Verbatim recognition & .458 & 7.62 \\
\hline & & & 2 & Inference recognition & .662 & 7.85 \\
\hline & & Science text & 1 & Verbatim recognition & .854 & 52.86 \\
\hline \multirow[t]{7}{*}{6 th } & \multirow{7}{*}{$\begin{array}{l}\text { Forward- } \\
\text { questioned }\end{array}$} & \multirow[t]{5}{*}{ Story } & 1 & Verbatim recognition & .455 & 8.36 \\
\hline & & & 2 & $\begin{array}{l}\mathrm{CAQ} \text { for inference } \\
\text { recognition }\end{array}$ & .692 & 10.14 \\
\hline & & & 3 & Inference recognition & .782 & 9.61 \\
\hline & & & 4 & text recall & .845 & 9.58 \\
\hline & & & 5 & Confidence in Japanese & .922 & 14.22 \\
\hline & & \multirow[t]{2}{*}{ Science text } & 1 & $\begin{array}{l}\text { Confidence in Science } \\
\text { studies }\end{array}$ & .504 & 10.17 \\
\hline & & & 2 & Inference recognition & .656 & 8.59 \\
\hline \multirow[t]{4}{*}{$6 \mathrm{th}$} & \multirow{4}{*}{$\begin{array}{l}\text { Backward- } \\
\text { questioned }\end{array}$} & \multirow[t]{2}{*}{ Story } & 1 & Verbatim recognition & .567 & 10.50 \\
\hline & & & 2 & Confidence in Japanese & .705 & 8.38 \\
\hline & & \multirow[t]{2}{*}{ Science text } & 1 & Verbatim recognition & .351 & 4.33 \\
\hline & & & 2 & $\begin{array}{l}\text { Confidence in Science } \\
\text { studies }\end{array}$ & .596 & 5.17 \\
\hline \multirow[t]{4}{*}{4 th } & \multirow[t]{4}{*}{ Non-question } & \multirow[t]{3}{*}{ Story } & 1 & Verbatim recognition & .575 & 16.26 \\
\hline & & & 2 & Inference recognition & .642 & .988 \\
\hline & & & 3 & text recall & .707 & 8.06 \\
\hline & & Science text & 1 & Verbatim recognition & .693 & 27.11 \\
\hline \multirow[t]{3}{*}{ th } & \multirow{3}{*}{$\begin{array}{l}\text { Forward- } \\
\text { questioned }\end{array}$} & \multirow[t]{2}{*}{ Story } & 1 & Verbatim recognition & .526 & 11.08 \\
\hline & & & 2 & $\begin{array}{l}\text { CAQ for inference } \\
\text { recognition }\end{array}$ & .928 & 58.82 \\
\hline & & Science text & 1 & Verbatim recognition & .428 & .749 \\
\hline \multirow[t]{3}{*}{4 th } & \multirow{3}{*}{$\begin{array}{l}\text { Backward- } \\
\text { questioned }\end{array}$} & Story & 1 & Verbatim recognition & .546 & 12.05 \\
\hline & & Science text & 1 & Verbatim recognition & .702 & 23.66 \\
\hline & & & 2 & Inference-recognition & .774 & 15.42 \\
\hline
\end{tabular}

COVA showed age effects $(F(1,65)=$ $3.961, p<.05)$.

Table 1 and Fig. 1 had also shown that for both of the 4th- and 6th-graders, direct influence evoked from their inference recognition of the science text on their CAQs were strongest when they were given no question aids, while least influence upon their CAQs were obtained as they were given question aids after each of the constituent paragraphs of the science text. The results of ANOCOVA were, however, marginally significant $(F$ $(1,65)=3.163, p<.10)$.

For inference recognition of story materials, similar results were obtained for the 6th-graders while just the reverse was the case for the 4th-graders: For the 4th-graders, correlation between recogni- tion remarks and their CAQs was maximized when they were given inserted question aids after each of the constituent paragraphs of the story materials, while least correlation was obtained for the non-questioned subjects. The results of ANOCOVA had shown that the question mode $\times$ subject interaction was significant $(F(2,65)=3.91, p<.05)$.

As shown in Table 2, 6th-grader's academic self-concepts had directly influenced upon their CAQs as those CAQ remarks were computed for their verbatim and inference recognition of the science text under either forward- or backward-question conditions. Furthermore, 6th-grader's self-concepts in Japanese had direct influence upon their verbatim recognition remarks under the forward- 


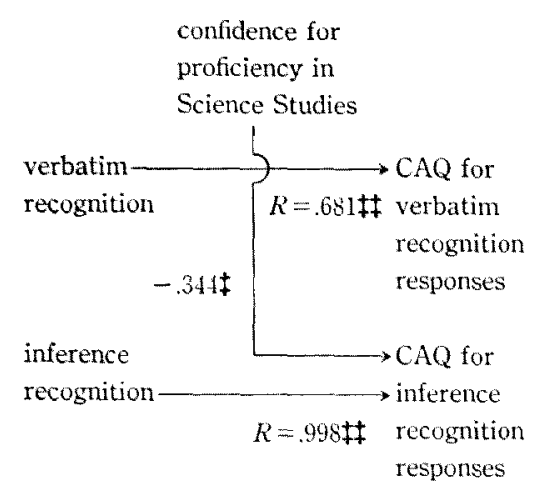

Non-Questioned 6th Graders (Science Text)

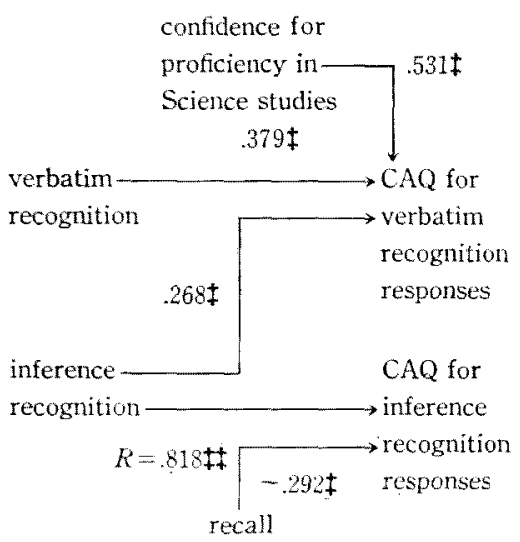

Forward Questioned 6th Graders (Science Text)

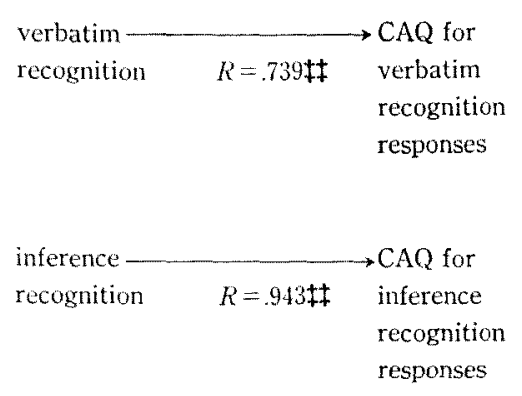

Non-Questioned 4th Graders (Science Text)

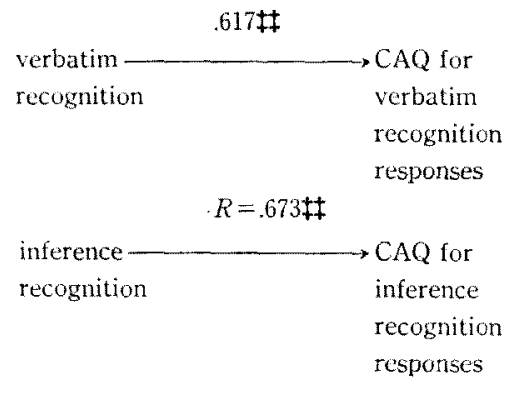

Furward Questioned th Graders (Science Text)

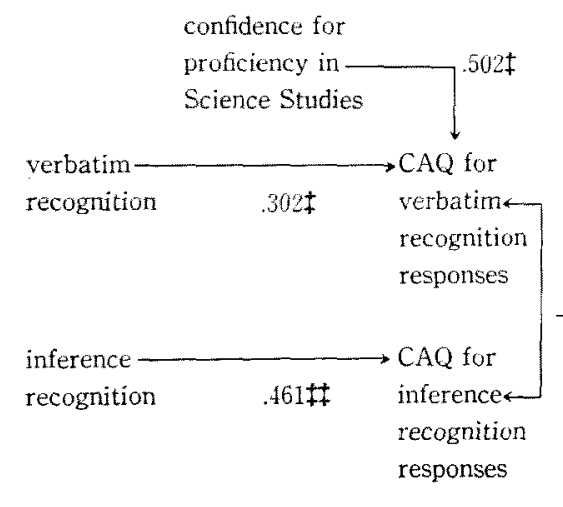

Backward Questioned 6th Graders (Science Text)

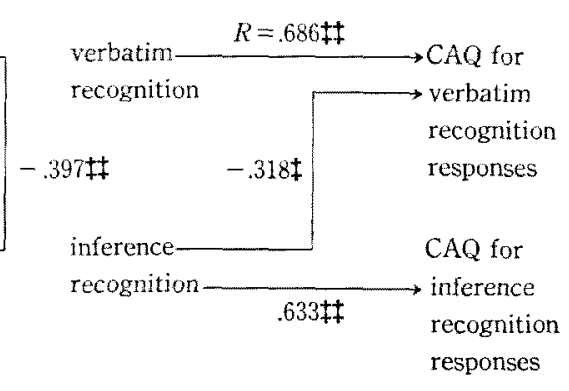

Backward Questioned 4th Graders (Science Text)

Fig. 1. Path-diagrams illustrating influences of recognition responses, recall and confidence in reader's own proficiency in Science study on their CAQs obtained for their text recognition remarks. 


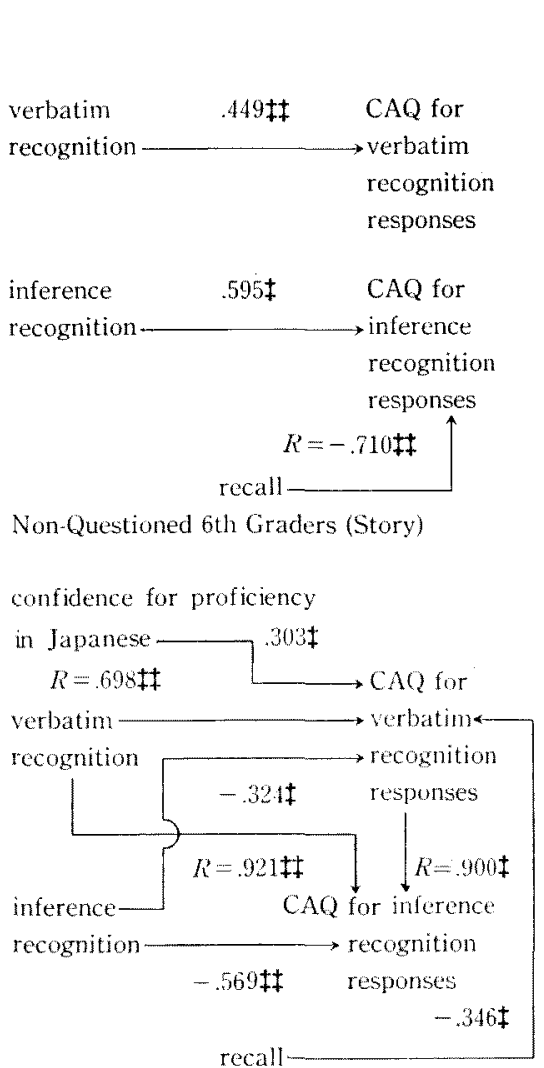

Forward Questioned 6th Graders (Story)

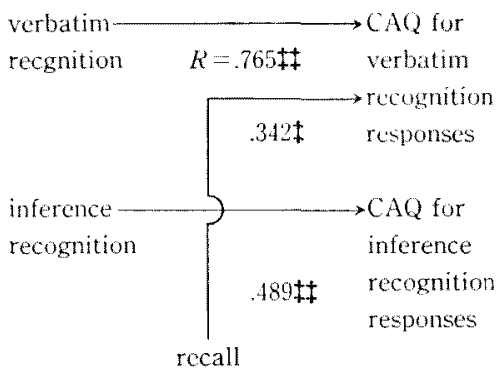

Backward Questioned 6th Graders (Story)

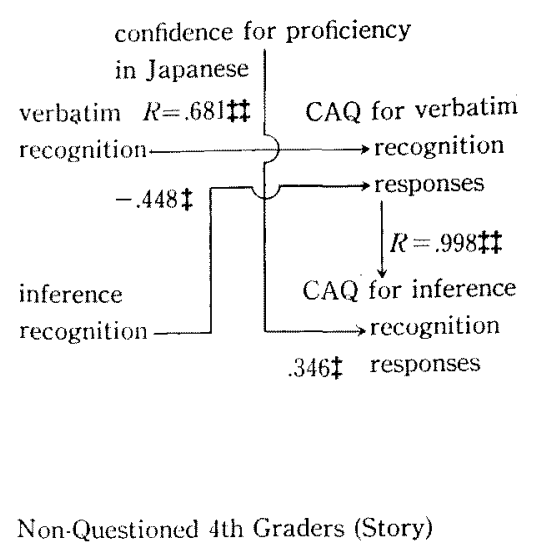

$.617 \ddagger$

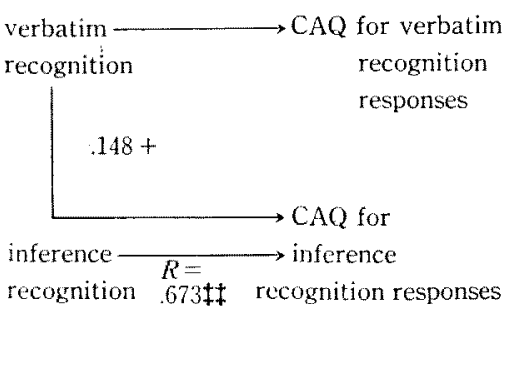

Forward Questioned 4th Graders (Story)

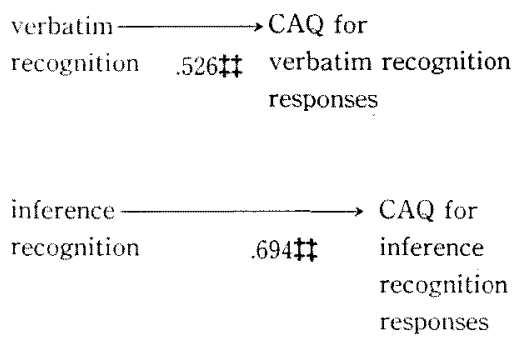

$\begin{array}{lll}\text { inference } & & \text { CAQ for } \\ \text { recognition } & \text { inference } \\ & \text { recognition } \\ & \text { responses }\end{array}$

Backward Questioned 4th Graders (Story)

Fig. 2. Path-diagrams illustrating influences of recognition responses, recall and confidence in reader's own proficiency in Japanese on their CAQs obtained for their story recognition remarks.

questioned conditions. For the 4th-graders, however, the path between subject's self esteems for Japanese and CAQs for verbatim recognition of story material was significant under the non-questioned conditions.
As each of the upper-left panels of Fig. 1 and Fig. 2 showed, the path from the rated confidence values obtained for non-questioned 6th-graders concerning their scientific self-concepts to their CAQs (path coefficients $=-.344$ ) is interesting, 
because its negative signs would seem to point to the fact that higher scientific selfconcepts evidenced by the 6th-graders would, unless their processing efforts were appropriately oriented by the question aids, adversely affect their efficiency in discriminating their own correct recognition responses from incorrect ones. If so, the 'illusion of knowing' would be evoked here, while for the 4th-graders, no significant influence of their confidence values upon their CAQ remarks were obtained.

Those results, taken together with higher path coefficients obtained for the 4thgraders between recognition remarks and their CAQs, would seem to point to the fact that the 4th-graders were less likely, as compared with the cases of 6 th-graders, to utilize both genre-specific and question-induced processing skills in reading, so that detrimental effects evoked from their retrieval failure upon their CAQs would be more likely.

As shown in Fig. 1 and Fig. 2, the pathes obtained for the 6th-graders between their text recall and the CAQs have shown negative signs, except those obtained for story materials under the backward question conditions (path coefficients $=342$ ). The results, taken together with those obtained for subject's academic self-concepts, would seem to point to the fact that the less resource consuming a text was, the more easily the 6 th-graders would retrieve it and the more confident they would be in correctness for their responses (e.g., Glenberg, Wilkinson, \& Epstein, 1982).

\section{Discussion}

Firstly, from those negative path coefficients obtained for the 6th-graders between their text recall and CAQs for their recognition remarks, and also from significant path coefficients obtained for either forward- or backward-questioned 6thgraders between their academic self- concepts and CAQ remarks, it could be said that unless text comprehension activities were appropriately oriented by the inserted question aids, retrieval efforts and their outcomes would mislead those 6th-graders into their overassessment of comprehension. Those negative signs obtained for inference recognition tasks could be ascribed to their failure in integrating but not in retention of premises (Halford, 1984).

Secondly, least causal relation was obtained for the backward-questioned 6thgraders between their verbatim recognition of scicnce text and their accuracy in discriminating their own correct responses from incorrect ones. The results was partially consistent with the hypothesis. For story materials, however, just the reverse was the case. Those contradictions could be explained in terms of what metacognitive experience was evoked from reader's processing tasks, processing efforts and also from their outcomes (e.g., Waern \& Askwall, 1981). Namely, since recognition of story text was dependent upon comprehension of temporal orderliness of representation of episodic units of the stories while those of science text was dependent upon how cause-effect relations among constituent units of the passage were realized by the readers (e.g., Yoshida, Ishitani, \& Tsuya, 1981), failure evidenced by the 6th-graders for their verbatim recognition of any episodic units of the story material would have more adversely affected, in comparison to the cases of science texts, their further question-induced processing, metacognitive activities and their outcomes including the CAQs. For science texts, however, it could be said that utilization of causal relationships among their episodic units or contexts would more likely, in comparison to the cases of stories, to compensate for subject's recognition failure as the 6th-graders were cued, by inserted question aids, to utilize those contexts or causal schemata in their com- 
prehension tasks. Those remarks were not always at odds with those that stressed lack of benefit of superior reading ability coupled with high knowledge (e.g., Recht \& Leslie, 1988).

Additionally, as presented in Table 1, correlations between recognition remarks obtained for inference recognition of the science text and those of verbatim recognition was lower, in comparison to the cases of story materials, although those lower correlations were not the case for forward questioned subjects.

Those results would seem to point to the above mentioned beneficial effects of causal relations among prose units upon inference recognition tasks because those causal relations would somehow compensate failure in retrieving episodic units of the science text, despite the fact that those compensatory effects would be less likely for the forward questioned subjects who had been induced to allocate their processing resources upon the questioned passage units as they read those episodic units of the science text.

Another issue that bears mention had stemmed from inconsistencies between the present result and other comprehension-monitoring studies. For example, the present result and those of Glenberg and Epstein (1985) had shown inaccuracy of skilled readers in monitoring their own learning and comprehension of texts. The results were at odds with those of Peterson, Swing, Braverman, and Buss (1982) which showed positive correlations between subject's monitoring of their mathematical learning and their subsequent achievements. Although no interpretation for those discrepancies can be made here, it certainly appears to be the case that those contradictory results could be ascribed to differences in procedures and also to those observed in scaffolding effects of subject's metacognitive knowledges upon their comprehension monitoring and other executive control activities. If so, a parsimonious explana- tion of subject's executive control activities could be provided by more elaborated description of developmental differences in subject's manner of both perceiving task characteristics and using macrostructures of the text materials.

A better understanding of those developments would necessitate further study of the interactions between subject's strategy use and instructional factors.

\section{References}

Baker, L., \& Brown, A. L. 1984 Metacognitive skills and reading. In $P$. D. Pearson (Ed.), Handbook of reading research. New York: Longman. Pp. 353-394.

Brown, A. L., \& Lawton, S. C. 1977 The feeling of knowing experience in educable retarded children. Developmental Psychology, 13, 364-370.

Glenberg, A. M., \& Epstein, W. 1985 Calibration of comprehension. Journal of Experimental Psychology: Learning, Memory, and Cognition, 11, $702-718$.

Glenberg, M.W., Wilkinson, A. C., \& Epstein, W. 1982 The illusion of knowing: Failure in the self-assessment of comprehension. Memory $\mathcal{G}^{\circ}$ Cognilion, 10, 597-602.

Halford, G.S. 1984 Can young children integrate premises in transitivity and serial order? Cognitive Psychology, 16, 65-93.

Henry, O, 1953 After twenly years. In O. Henry The complete works of 0 . Henry. Vol. 1. New York: Doubleday \& Company. Pp. 88-91.

Mitsuda, M. 1987 Effects of processing variables on judgements of text leaming. Psychologia, 30, 21-33.

Mitsuda, M., Kurisu, K., \& Takeichi, C. 1985 Effects of inserted question aids and experimenter provided perspectives on text memory. Psychologia, 28, 46-55.

Mize, J. 1980 The relationships between reading performance and awareness of comprehension of textbook passages. In M. L. Kaul \& A. J. Moe (Eds.), Perspectives on reading research and instruction. Washington, D. C. National Reading Conference.

Peterson, P. L., Swing, S. R., Braverman, M. T., \& Buss, R. 1982 Student aptitudes and their reports of cognitive processes during direct instruction. Journal of Educational Psychology, 74, 
535-574.

Recht, D. R., \& Leslie, L. 1988 Effects of prior knowledge on good and poor reader's memory of text. Joumal of Educational Psychology, 80, 16-20.

Wacrn, Y., \& Askwal, S. 1981 On some sources of metacomprehension. Scandinavian Journal of
Psychology, 22, 1-25.

Yoshida, H., Ishitani, T., \& Tsuya, N. 1981 Effects of theme presentation on discourse comprehension: An examination of input modality. Research Bulletin of Humanistic Science, Faculty of Edtcalion, Miyazaki University, 10, 45-54.

(Received May 9, 1988; accepted Sept. 9, 1989) 